\title{
IGNITION LENGTH STUDY OF JP-8 + 100 IN A SUPERSONIC DUCT
}

\author{
M. L. Bateup \\ The University of Queensland \\ Brisbane, Queensland, Australia
}

\begin{abstract}
In scramjets, hydrocarbon fuels are being considered for their endothermic potential and for use in flights where compact, volume critical designs are required at flight speeds at Mach $5+$. Long-chain hydrocarbon (LCHC) fuels, like aviation kerosene, have handling and storage advantages over hazardous and volatile fuels, like hydrogen, that are more aligned with current flight systems. This research investigates the conditions under which kerosene fuel (JP-8 + 100) may be used in a supersonic duct at a hypervelocity impulse facility. Experimental data on kerosene ignition lengths for temperatures in the range 1100-1550 K, pressure of $1 \mathrm{~atm}$, and equivalence ratios of $0.2-2.5$ are compared with ignition delay correlations from literature.
\end{abstract}

\section{INTRODUCTION}

This paper reports on a study of the ignition length of long chain hydrocarbon (kerosene) based aviation fuel in a scramjet combustor. This is the first part of an investigation examining the effects of adding supplementary ethylene to the aviation kerosene. Ethylene combustion in a supersonic flow stream produces a vigorous and rapid combustion onset, much like that of hydrogen [1]. Improving the LCHC ignition length would result in a shorter combustor and reduction in associated skin-friction drag and heat transfer. The LCHC fuels suffer certain drawbacks when applied to a scramjet engine where the airflow through the combustor is of the order of $2 \mathrm{~km} / \mathrm{s}$. Chief amongst these are the time required for ignition to commence and thermal stability of the fuel [2]. The long delay for LCHC fuel ignition results in scramjet combustors of the order of meters long. This is prohibitive for a volume-constrained aircraft. By augmenting LCHC with the addition of ethylene, it may be expected to react more like ethylene and result in improvements to combustor efficiencies for LCHC fuels. Before ethylene augmentation tests can be examined, a baseline for the ignition length

This is an Open Access article distributed under the terms of the Creative Commons Attribution License 4.0, which permits unrestricted use, distribution, and reproduction in any medium, provided the original work is properly cited. 
of LCHC fuel (without ethylene augmentation) in a scramjet combustor must be established. The particular LCHC fuel used was JP-8 +100 .

In order to test LCHC fuels, ground-test facilities should be able to deliver fuel at an equivalent condition as experienced in flight. It is reported [3] that continuous flow facilities require in the order of $2 \mathrm{MW}$ of power per kilogram per second of feed fuel to replicate the appropriate fuel injection composition, temperature, and pressure. Furthermore, for the quantity of fuel required, the facility requires additional infrastructure to manage fuel preheating as well as condensers and containment to deal with possible failures of the system. Impulse facilities have the benefit of extremely short test duration, such that the amount of fuel injected per test is of the order of a few grams for a few milliseconds, thereby avoiding hefty power and infrastructure requirements. The drawback with impulse facilities is the same short test duration which limits the use of slowignition liquid hydrocarbon fuels. There is usually insufficient time for the fuel to be injected, vaporize, mix, and react within the available length of combustor.

This paper presents the results of an ignition length study with JP-8 +100 using a fuel vaporizer suitable for use with an impulsive hypervelocity test facility [3]. The results of tests on JP-8 +100 with ethylene augmentation are the subject of subsequent publication [4].

Facilities such as heated reflected shock tubes and well-stirred reactors are better suited to investigate ignition delay correlations and chemical kinetics than the supersonic duct combustion chamber used for this study. The goal of this research was not to replicate ignition correlations, but to investigate how well those correlations may be applied to a generic supersonic duct.

\section{EXPERIMENTAL SETUP}

Flow within the supersonic duct was generated by the University of Queensland's T4 free piston reflected shock-tube impulse facility [5-7]. The representative nozzle-supply conditions were $35 \mathrm{MPa}$ and $3.2 \mathrm{MJ} /(\mathrm{kg}$ air) which was expanded to Mach 6.7 at the nozzle exit and was further processed by a pair of compression wedges into the model. The experiments were conducted at a duct entry condition of Mach 2.7, static pressure of $85-135 \mathrm{kPa}$, and static temperature between 1100 and $1550 \mathrm{~K}$. The principal variable controlling ignition was the temperature; so, a wide range in this parameter was desirable. In order to limit the test-to-test variation in ignition length due to pressure, the target duct entry pressure was a nominal $1 \mathrm{~atm}$. Where $1 \mathrm{~atm}$ was not achieved, ignition length data was scaled by an inverse pressure relation, $P^{-1}$.

The experimental model [8] consisted of a set of inclined plate compression wedges ahead of a parallel combustion duct, with a central strut fuel injector (Fig. 1), where flow is from left to right. The model was $1.75 \mathrm{~m}$ in length, with a 1.2 -meter combustor of $0.1 \times 0.47 \mathrm{~m}$ cross section. The air entering the 


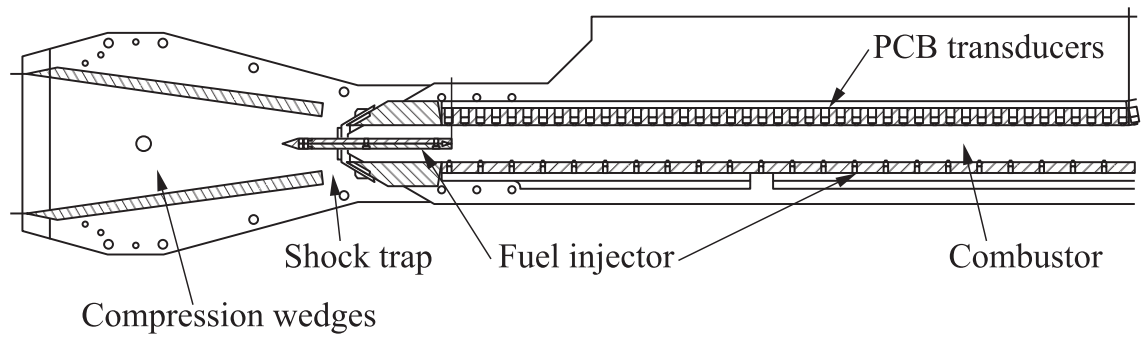

Figure 1 Schematic of the experimental model (adapted from [9])

combustion duct was in the range $1810-1970 \mathrm{~m} / \mathrm{s}$ for the $3-3.5 \mathrm{MJ} / \mathrm{kg}$ condition. For ignition to be observed within the duct, the ignition delay needed to be less than $0.7 \mathrm{~ms}$ at $1 \mathrm{~atm}$. Based on ignition delay correlations for JP-8 and JetA [10-14], it was reasonable to expect JP-8 + 100 to ignite within the duct at temperatures $1300 \mathrm{~K}$ and above.

A fuel supply system was developed [4] that was capable of delivering gaseous blends of hydrocarbon fuels within the $2-3 \mathrm{~ms}$ test time available at the impulse facility. JP- $8+100$ was vaporized prior to injection into the supersonic duct by means of a heated Ludwig tube commissioned for this study. The vaporizer system was capable of blending gaseous ethylene and liquid kerosene. The thermal control of the system moderated the fuel between 650 and $700 \mathrm{~K}$ such that two-phase gaseous-liquid regions were avoided. These were detrimental to the operation of the system, as was the deposition of gum and sooting from JP-8 +100 pyrolysis and reformation.

Pressure was measured at 20-millimeter intervals along the duct. It was the primary means of observing ignition and combustion. Two baseline cases were established. One was a fuel-off case with air as the test gas and no fuel injection, and the other was a supressed combustion case. The later occurs when fuel is injected into a nitrogen test gas to allow the effect of fuel addition to be isolated in the absence of combustion. In subsequent fuel-on tests, any pressure rise in excess of the baseline cases may be attributed to combustion. The ignition length was determined as the axial location where the fuel-on coefficient of pressure $\left(C_{P}\right)$ departed from the baseline cases in a sustained pressure rise which achieved and maintained an increase of $0.1 C_{P}$ above the baseline at the end of the duct. The reference pressure and dynamic pressure used in the calculation of $C_{P}$ were taken at the duct entry conditions. Ignition was assumed to occur within the mixing layer. This was assumed to be, to first approximation for this experimental configuration, parallel with and at the same transverse location as the surface of the strut injector [9]. A correction was applied to the measured ignition length to account for the axial displacement as the pressure increment propagated across the duct by means of a Mach wave to be measured at the wall. For the presented 
examples, this was a 49-millimeter axial off set. While only first-order accurate, this correction was consistent across all tests.

Experimental uncertainty of key parameters was $11 \%, 2 \%$, and $5 \%$ for duct entry temperature, pressure, and Mach, respectively. The uncertainty of coefficient of pressure, $C_{p}$, in the ignition region was $10 \%$. Derivations of the uncertainties are presented in the aggregated thesis [4]. In total, 193 experimental tests were conducted, and results at comparable conditions were averaged to improve accuracy.

\section{RESULTS AND DISCUSSION}

The tests were carried out on $94 \%-100 \%$ molar blends of JP- $8+100$ with ethylene. To differentiate between blended fuels, the nomenclature used to refer to
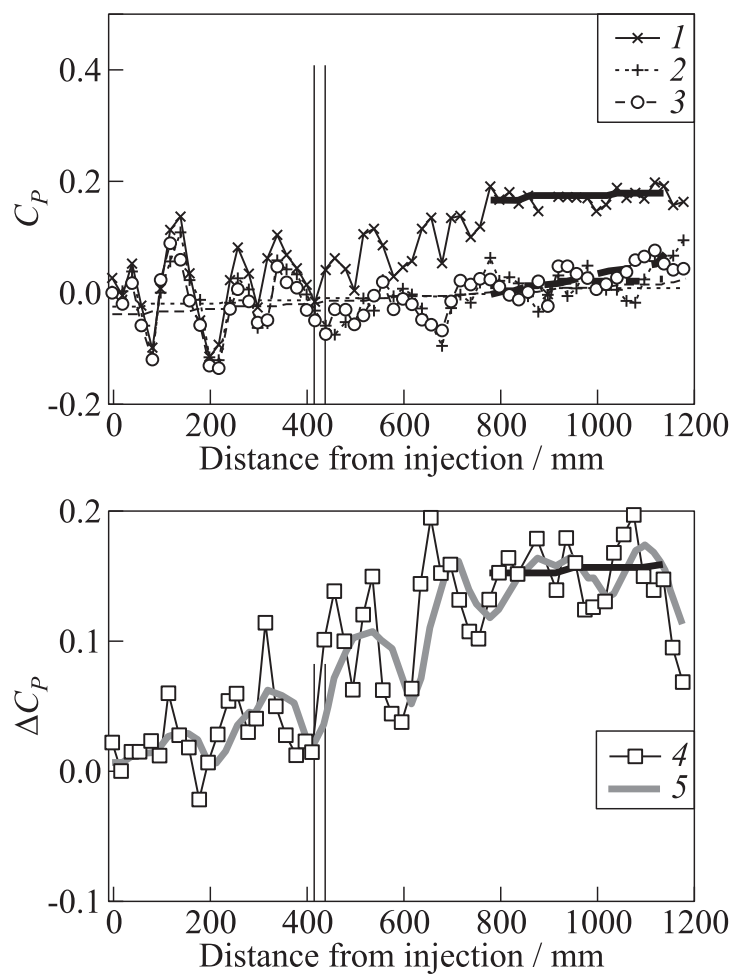

Figure $2 C_{P}$ vs. length for JP-8 +100 ignition length at $1530 \mathrm{~K}: 1$ - fuel on, $\overline{C_{P}}=0.17 ; 2-$ fuel off, $\overline{C_{P}}=0.02 ; 3-$ fuel into $\mathrm{N}_{2}, \overline{C_{P}}=0.02 ; 4-\Delta C_{P}$, $\overline{\Delta C_{P}}=0.15$; and 5 - four-point running average 
each blend is ' $\mathrm{C}_{n} \mathrm{H}_{m}$ ' for the carbon:hydrogen ratio on a molar basis. JP-8 +100 was modeled as $\mathrm{C}_{12} \mathrm{H}_{24}$ after [15]. Where a fuel percentage is identified, it refers to the mole fraction of JP-8 +100 and the complementary percentage is ethylene. The results from blended fuel tests of $50 \%-86 \%$ ethylene are to be reported in subsequent papers.

An example of a test with $100 \% \mathrm{JP}-8+100$ fuel at an equivalence ratio of 1.5 , injected into $1530 \mathrm{~K}$ airflow at Mach 2.7 is presented in Fig. 2, where flow is from left to right. The figure presents the variation in $C_{p}$ along the duct commencing from the point of fuel injection. The baseline cases of fuel-off and suppressed combustion cases are shown along with the fuel-on case. A strong expansion and shock structure within the duct is evident. These are the results of expansions and recompression shocks which occur at the step-change in geometry at the rear of the central strut. The difference in $C_{p}\left(\Delta C_{p}\right)$ between the fuel-on and the baseline cases is also presented, along with a four-point running average.
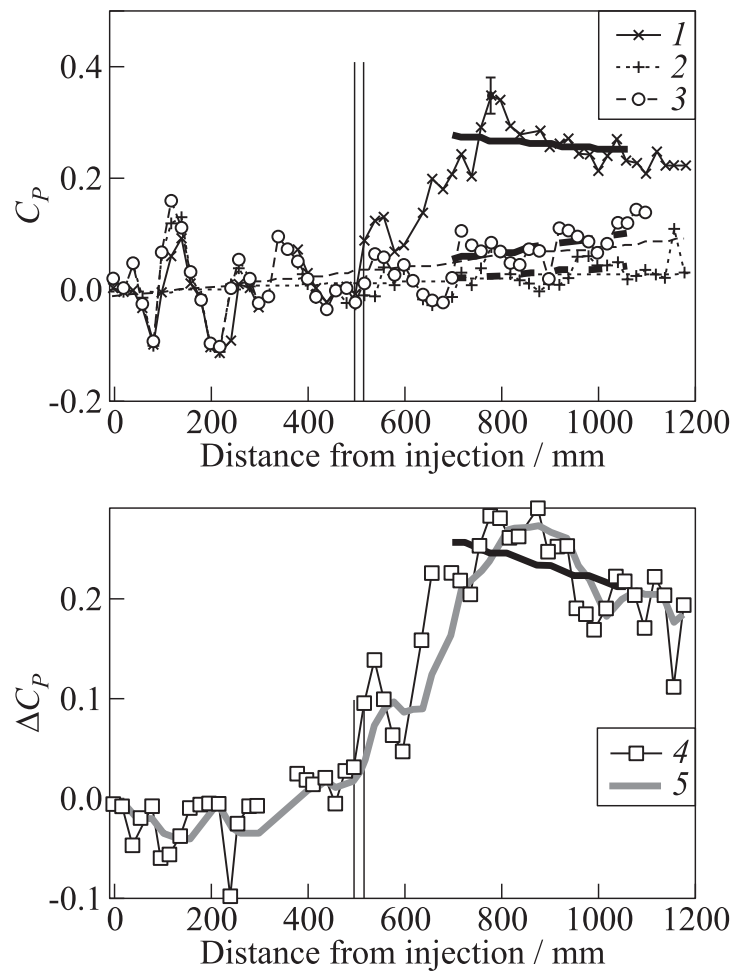

Figure $3 C_{P}$ vs. length for JP-8 +100 ignition at $1410 \mathrm{~K}$ : 1 - fuel on, $\overline{C_{P}}=0.26$; 2 - fuel off, $\overline{C_{P}}=0.03 ; 3-$ fuel into $\mathrm{N}_{2}, \overline{C_{P}}=0.07 ; 4-\Delta C_{P}, \overline{\Delta C_{P}}=0.23$; and 5 - four-point running average 

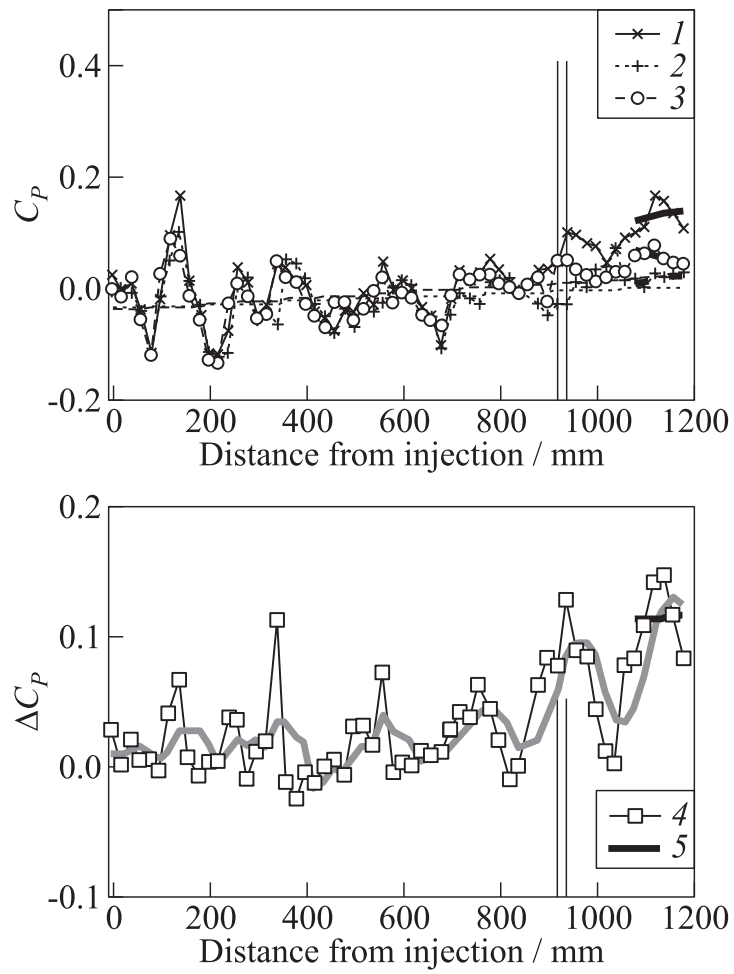

Figure $4 C_{P}$ vs. length for JP-8 +100 ignition at $1320 \mathrm{~K}: 1-$ fuel on, $\overline{C_{P}}=0.13$; 2 - fuel off, $\overline{C_{P}}=0.01 ; 3-$ fuel into $\mathrm{N}_{2}, \overline{C_{P}}=0.05 ; 4-\Delta C_{p}, \overline{\Delta C_{p}}=0.11$; and 5 - four-point running average

The increase in $\Delta C_{p}$ of 0.15 above the baseline demonstrates that a sustained pressure rise in a supersonic duct was achieved. This result also demonstrates that the fuel supply vaporizer operated satisfactorily and may be used to conduct further research. The ignition length for this particular test occurred between 417 and $437 \mathrm{~mm}$ (less than 49-millimeter correction).

At a temperature of $1410 \mathrm{~K}$, it was observed (Fig. 3) that ignition occurred further towards the rear of the duct, as expected, between 497 and $517 \mathrm{~mm}$.

When the temperature was reduced to $1320 \mathrm{~K}$, it was observed (Fig. 4) that ignition occurred further towards the rear of the duct between 917 and $937 \mathrm{~mm}$.

These results were consistent with the anticipated result of Arrhenius-type ignition delay correlations $[10-14,16-20]$ where ignition delay is a strong function of temperature.

Ignition length measurements were made with a duct inlet condition between 1100 and $1550 \mathrm{~K}$ at pressures from 85 to $135 \mathrm{kPa}$, and equivalence ra- 


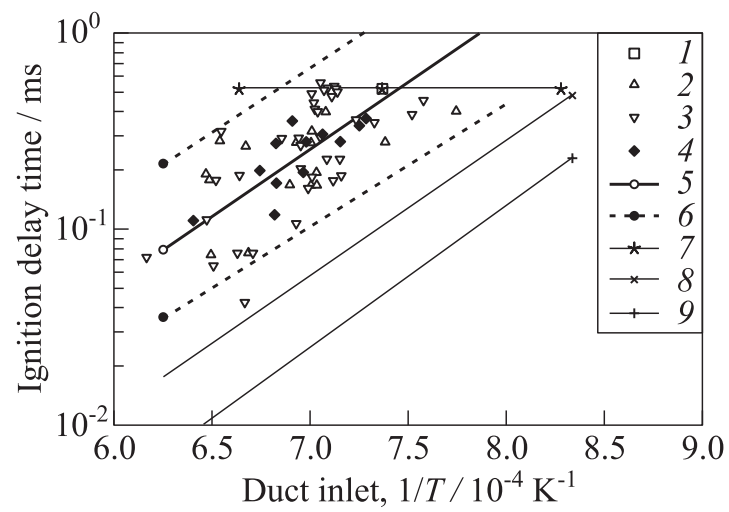

Figure 5 Experimental data for the ignition delay of JP-8 +100 in a supersonic duct: $1-\mathrm{C}_{11} \mathrm{H}_{m}(90 \%) ; 2-\mathrm{C}_{11.5} \mathrm{H}_{m}(94 \%-96 \%) ; 3-\mathrm{C}_{11.8} \mathrm{H}_{m}(97 \%-99 \%) ; 4-$ $\mathrm{C}_{12} \mathrm{H}_{m}(99.8 \%) ; 5$ - least squares fit to JP8 + 100 data (this work); 6 - 95 percent confidence interval; 7 - temperature uncertainty; $8-\mathrm{C}_{2} \mathrm{H}_{4}$ (ethylene) [18]; and $9-$ $\mathrm{C}_{2} \mathrm{H}_{4}[17]$. All data are scaled to 1 atm by $P^{-1}$

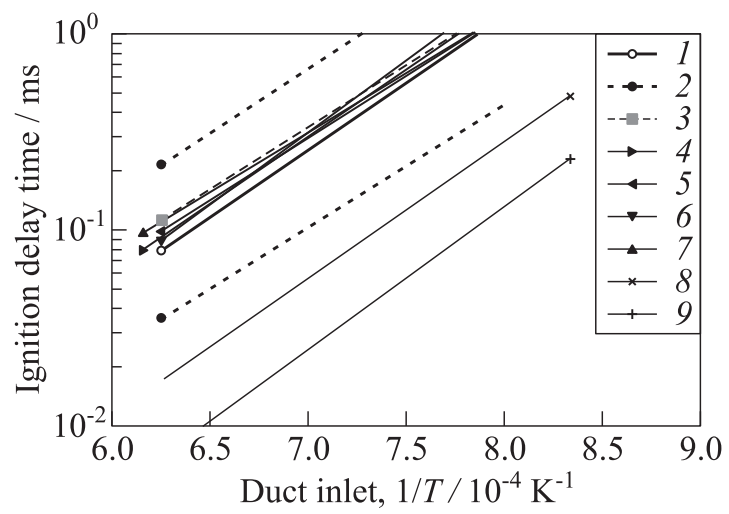

Figure 6 Comparison of the JP- $8+100$ fit with Jet-A and JP- 8 correlations: $1-$ least squares fit to JP8 + 100 data (this work); $2-95$ percent confidence interval; 3 - JP-8 [13]; 4 - Jet-A [12]; 5 - Jet-A [11]; 6 - Jet-A [14]; 7 - T-1 (Russian Jet-A) [10]; $8-\mathrm{C}_{2} \mathrm{H}_{4}[18]$; and $9-\mathrm{C}_{2} \mathrm{H}_{4}$ [17]. All data are scaled to $1 \mathrm{~atm}$ by $P^{-1}$

tios $0.2-3.0$. The experimental data are presented in Fig. 5 along with a least squares Arrhenius fit and 95 percent confidence interval. The ignition 'length' has been converted to an ignition 'delay' by the duct inlet velocity and uses an inverse temperature abscissa. The regression fit and confidence interval are compared with correlations for JP-8 [13] and Jet-A [10-12,14] in Fig. 6. 
All experimental data and correlations are scaled to 1 atm for the comparison.

It was observed that there is significant scatter within the data for a given temperature, of the order of $45 \%$, which represents the variation due to the experimental apparatus for measuring ignition length in a scramjet duct, as well as the inherent repeatability of ignition delay studies. Flow within the duct has inherent nonuniformities and is not a homogenous fuel-air mixture as in shock-tube studies of ignition delay (see, for example, [13]) or with continuous control over flow variables (such as in [16]). Three-dimensional gasdynamic structure of supersonic airflow in these experiments can have a significant impact on the accuracy of the results which is addressed in the aggregated thesis [4]. However, the amount of scatter is consistent with the 42 percent reported in [19] as typical variation in length for shock-tube ignition delay studies. The Arrhenius fit to the data agrees well with the presented correlations. The slope of the Arrhenius fit in Fig. 6 (representing a suggested activation energy of $29.3 \pm 8.9 \mathrm{kcal} / \mathrm{mol}$ for the fuel) is in keeping with those of JP-8 and Jet-A. This was an anticipated result as the base fuel-stock is from the same family of aviation kerosene. The large uncertainty on activation energy was due to the amount of experimental scatter, suggestive of apparatus-dependent phenomena. Despite the scatter, the apparent activation energy is in agreement with the reported values for JP-8 (29 kcal/mol [13]) and Jet-A (27.8 [11], 29.2 [10], and $32.7 \mathrm{kcal} / \mathrm{mol}[12])$. All of the tabulated activation energies lie within the experimental uncertainty. Units of $\mathrm{cal} / \mathrm{mol}$ are used for consistency with previously reported works.

The strong similarity between the reported correlations [10-14] and the experimental data demonstrates that the ignition delays observed in the impulse facility correlate with those previously observed in other facilities. The correlations closely predict the ignition delay and activation energy of the fuel at experimental conditions of $1 \mathrm{~atm}$ and temperature range 1250-1600 K. The correlations for ethylene $[17,18]$ are depicted in Figs. 5 and 6 for comparison with the future ethylene augmentation study.

The point of difference in the current study is that the experimental data were obtained from a supersonic duct, with nonuniform flow and nonhomogeneously mixed fuel. This is different from how the ignition delay studies are typically made. They use a reflected shock tube with a homogeneous fuel and oxygen mixture which is subjected to a sudden rise in temperature and pressure from a reflected shock wave [13]. The resulting ignition delay correlations are regarded to be applicable under similar pressure and temperature conditions to those of the experiments from which they were derived. When the correlations were scaled to atmospheric pressure, they matched the experimental data. Therefore, the JP-8 +100 study justifies the use of ignition delays found from conventional shock tube studies for application in a scramjet duct. This is strong indication that the JP-8 +100 ignition delay is reaction limited, not mixing limited. 


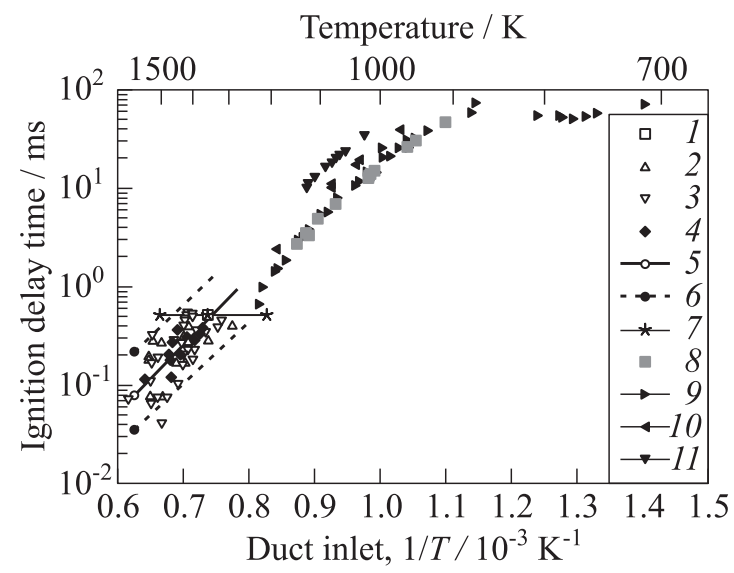

Figure 7 Comparison of JP-8 +100 data with JP-8 and Jet-A data from [20]: 1 $\mathrm{C}_{11} \mathrm{H}_{m}(90 \%) ; 2-\mathrm{C}_{11.5} \mathrm{H}_{m}(94 \%-96 \%) ; 3-\mathrm{C}_{11.8} \mathrm{H}_{m}(97 \%-99 \%) ; 4-\mathrm{C}_{12} \mathrm{H}_{m}$ (99.8\%); 5 - least squares fit to JP8 + 100 data (this work); 6 - 95 percent confidence interval; 7 - temperature uncertainty; 8 - JP-8 [20]; 9 - Jet-A [20]; 10 - Jet-A $(\phi=0.5)[20]$; and $11-$ Jet-A $\left(10 \% \mathrm{O}_{2}\right)[20]$. All data are scaled to $1 \mathrm{~atm}$ by $P^{-1}$

The experimental data are compared with ignition delay data for JP-8 and Jet A from a heated shock tube across the range 715-1229 K [20] in Fig. 7. Both sets of data display a consistent activation energy in the region above $900 \mathrm{~K}$. Below $900 \mathrm{~K}$, there is evidence of the negative temperature coefficient region, where the slope of the Arrhenius-like exponential temperature dependency is reversed $[12,20-22]$. While the regression fit to the JP- $8+100$ data should not be extrapolated beyond the range of the experimental data (1100 to $1600 \mathrm{~K})$, it is shown to be consistent with JP-8 data between 1000 and $1229 \mathrm{~K}$.

The data [20] show the difference in ignition delay at equivalence ratio of $\phi=1$ and 0.5 . This reduction in $\phi$ had the effect of increasing the ignition delay by $40 \%$ at $1080 \mathrm{~K}$. The same influence of $\phi$ on ignition delay is reported for Jet A and JP-8 from shock tube studies $[11,12,23,24]$. Equivalence ratio variation may explain the scatter observed in the experimental results for JP- $8+100$. Differences in induction times between stoichiometric, fuel-lean, and fuel-rich mixtures also have an effect on ignition delay $[11,12]$.

\section{CONCLUDING REMARKS}

The JP-8 +100 experimental study shows that traditional correlations can be used to effectively predict the ignition delay times of LCHC fuels in a scramjet 
combustor, provided pressure effects are taken into account. This is an important finding which allows the correlations to be used with confidence in scramjet combustor design and computational fluid dynamics simulations of LCHC combustion in supersonic ducts. The fact that multiple Jet-A and JP-8 correlations are closely aligned to the regression fit gives confidence that the calculated duct inlet temperatures are near the middle of the measurement uncertainty for temperature and not at the \pm 11 percent limit. The correlations are a validation of the regression and the temperature calculations.

The data presented for JP- $8+100$ conclusively show that the pressure rise occurred can be attributed to the heat release from combustion. The examples represented 0.94 to 1.0 mole fraction $\mathrm{JP}-8+100$ mixtures. This demonstrates that the fuel injection system can be used to study combustion of JP- $8+100$ in a supersonic flow stream in an impulse facility. For the current experimental configuration, the earliest possible point of ignition was limited by the presence of a strong expansion and shock system extending $100 \mathrm{~mm}$ downstream of the strut injector.

Combustion of JP- $8+100$ was found to have an apparent activation energy of the order of $29 \mathrm{kcal} / \mathrm{mol}$. The comparison with ignition correlations from premixed homogenous tests provides good evidence that JP- $8+100$ combustion in a supersonic flow stream is reaction-limited.

The ignition delay and ignition temperature is not an absolute property of a substance. Therefore, empirical relations will have an inherent degree of uncertainty related to the nature of the test apparatus and methods used for their determination [25]. Yet, despite the scatter in the data, the results of the present study correlate well with the published correlations for JP-8 and Jet-A from a broad range of fuel-stocks and researchers.

\section{ACKNOWLEDGMENTS}

This work was made possible through the support of the Australian Department of Defence, Defence Science and Technology Organisation, and the University of Queensland, as well as the on-going encouragement of Adjunct Prof. A. Paull and Prof. D. Mee.

\section{REFERENCES}

1. Paull, A., R. J. Stalker, and D. J. Mee. 1995. Experiments on supersonic combustion ramjet propulsion in a shock tunnel. J. Fluid Mech. 296:159-183.

2. Edwards, T. 2006. Cracking and deposition behaviour of supercritical hydrocarbon aviation fuels. Combust. Sci. Technol. 178(1-3):307-334. 
3. Maurice, L., T. Edwards, and J. Griffiths. 2001. Liquid hydrocarbon fuels for hypersonic propulsion. Scramjet propulsion. Eds. E. T. Curran and S. N. B. Murthy. Progress in austronautics and aeronautics ser. Reston, VA: AIAA. 1293:757-822.

4. Bateup, M. L. 2012. Ethylene augmentation of JP-8 + 100 in a supersonic combustor. The University of Queensland. PhD Thesis.

5. Stalker, R. J. 1990. Recent developments with free piston drivers. 17th Symposium (International) on Shock Waves and Shock Tubes Proceedings. Bethlehem, PA: American Institute of Physics. 96-105.

6. Stalker, R. J., and R. G. Morgan. 1998. The University of Queensland free piston shock tunnel T4 - initial operation and preliminary calibration. 4th Space Engineering Symposium (International). Brisbane, QLD, Australia.

7. Paull, A., and R. J. Stalker. 2000. Scramjet testing in the T3 and T4 hypersonic impulse facilities. Scramjet propulsion. Eds. E. T. Curran and S. N.B. Murthy. Progress in austronautics and aeronautics ser. Reston, VA: AIAA. 1293:1-46.

8. Jacobs, P. A. 1989. A scramjet model for pressure scaling studies. St. Lucia, QLD, Australia: Department of Mechanical Engineering, The University of Queensland. Report 2189.

9. Razzaqi, S. A. 2011. Oxygen enrichment in a hydrogen fuelled scramjet. The University of Queensland. PhD Thesis.

10. Zimont, V.L., and Y.M. Trushin. 1967. Ignition lag of hydrocarbon fuels at high temperatures. Combust. Explo. Shock Waves 3(1):51-56.

11. Starikovskii, A. Yu., V. I. Khorunzhenko, N. S. Mazko, et al. 2003. Investigation of thermodynamic properties and ignition of kerosene-air mixtures behind reflected shock wave front. Moscow: Moscow Institute of Physics and Technology. Technical Report.

12. Dean, A. J., O. G. Penyazkov, K. L. Sevruk, and B. Varatharajan. 2007. Autoignition of surrogate fuels at elevated temperatures and pressures. Proc. Combust. Inst. 31(2):2481-2488.

13. Kahandawala, M. S. P., M. J. DeWitt, E. Corporan, and S. S. Sidhu. 2008. Ignition and emission characteristics of surrogate and practical jet fuels. Energ. Fuel. 22(6):3673-3679.

14. Burcat, A., E. Olchansky, U. Steil, et al. The pursuit after a model of kerosene combustion: An experimental and modelling study of ignition delay time of kerosene. Technion - Israel Institute of Technology-DLR. Unpubl., personal communication.

15. Wang, T.-S. 2001. Thermophysics characterization of kerosene combustion. J. Thermophys. Heat Tr. 15:140-147.

16. Mullins, B. P. 1952. Studies on the spontaneous ignition of gas turbine fuels injected into a hot gas stream. University of London. PhD Thesis.

17. Baker, J.A., and G.B. Skinner. 1972. Shock-tube studies on the ignition of ethylene-oxygen-argon mixtures. Combust. Flame 19:347-350.

18. Colket III, M. B., and L. J. Spadaccini. 2001. Scramjet fuels autoignition study. J. Propul. Power 17(2):315-323.

19. Shen, H.-P. S. 2008. Shock tube ignition delay studies of hydrocarbon components found in jet fuels. Rensselaer Polytechnic Institute. PhD Thesis. 
20. Vasu, S. S., D. F. Davidson, and R. K. Hanson. 2008. Jet fuel ignition delay times: Shock tube experiments over wide conditions and surrogate model predictions. Combust. Flame 152:125-143.

21. Dagaut, P., and M. Cathonnet. 2006. The ignition, oxidation, and combustion of kerosene: A review of experimental and kinetic modelling. Prog. Energ. Combust. Sci. 32:48-92.

22. Westbrook, C. K., W. J. Pitz, O. Herbinet, H. J. Curran, and E. J. Silke. 2009. A comprehensive detailed chemical kinetic reaction mechanism for combustion of $n$-alkane hydrocarbons from $n$-octane to $n$-hexadecane. Combust. Flame 156:181199.

23. Puri, P., F. Ma, J.-Y. Choi, and V. Yang. 2005. Ignition characteristics of cracked JP-7 fuel. Combust. Flame 142:454-457.

24. Kumar, K., and C.-J. Sung. 2010. An experimental study of the autoignition characteristics of conventional jet fuel/oxidizer mixtures: Jet-A and JP-8. Combust. Flame 157:676-685.

25. Spadaccini, L. J., and J. A. Tevelde. 1982. Autoignition characteristics of aircrafttype fuels. Combust. Flame 46:283-300. 